\title{
Impact of Land Right Arrangements on the use of Irrigation Resources in the Lower Niger River Basin Development Authority of Nigeria
}

\author{
Ajiboye Abiodun'1, A. 0 Adekunmi' ${ }^{1}$, . A Adeleke' ${ }^{2}$, A. 0 Awoyemi ${ }^{1}$ \\ 1Department of Agricultural Economics and Extension Services, Ekiti State University, Ado Ekiti, Nigeria \\ 2Department of Agricultural Economics, Ladoke Akintola University Of Technology, Ogbomoso, Nigeria
}

\begin{abstract}
How to cite this paper: Ajiboye Abiodun |A. O Adekunmi | O. A Adeleke | A. 0 Awoyemi "Impact of Land Right Arrangements on the use of Irrigation Resources in the Lower Niger River Basin Development Authority of Nigeria" Published in International Journal of Trend in Scientific Research and Development (ijtsrd), ISSN: 24566470, Volume-3 | Issue-3, April 2019, pp.637-641, URL: http://www.ijtsrd.co $\mathrm{m} /$ papers/ijtsrd229 27.pdf

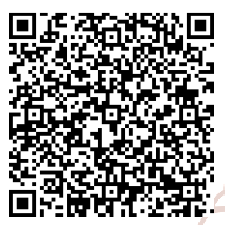

IITSRD22927
\end{abstract}

Copyright (C) 2019 by author(s) and International Journal of Trend in Scientific Research and Development Journal. This is an Open Access article distributed under the terms of the Creative Commons

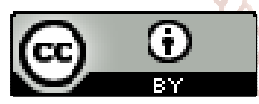
Attribution License (CC BY 4.0) (http://creativecommons.org/licenses/ by $/ 4.0$ )

\section{INTRODUCTION}

Land right characteristics affect access to land and access to land on the other hand affects food productivity in any nation Agwu et. al.(2010) Vuuren and Ysselstein (1986).Although Land tenure and food security have traditionally been two separate areas of research (Maxwell and Wiebe, 1999), yet there is an important relationship between the two. One of the means through which food productivity can be quickly achieved in any nation is to complement rain-fed system of farming with irrigation activities in key producing basins of such countries. However irrigation farming productivity is being threatened everywhere due to climate change, the emerging imbalance between water need and population explosion, declining soil fertility and difficulty encountered in the process of land allocation e.t.c. The land right characteristics of the Nigerian irrigation system is another peculiar factor that limits the striving towards being a giant in food security. Generally, availability of water is paramount to the effective irrigation systems, and the productivity of water will depend on several factors including the quantity and quality of complementing inputs, physical characteristics of plots, etc.
Some of these factors (e.g. soil quality due to investment in soil conservation) may in turn depend on a farmer's perceived tenure security of such plots which they cultivate.

While some argued that tenure differences and income levels of migrants and indigenous landowners play a critical role in investments in land improvements, Victor Owusu et al (1997). There is the submission, too that the literatures on tenure issues and food security issues are not well connected and the scientific evidence on the causal links between tenure security and food security is very limited, Stein and Hosaena (2016). A significant connection, therefore ,exits between land scarcity in many nations of the world and particularly in poor countries facing high climate risks, and the policy relevance of the links between access to land, tenure security and food security. security (Godfray et al.,2010 ; Lambin and Meyfroidt, 2011 ;Holden and Otsuka, 2014)

For this reason, too much emphasis cannot be made on the linkage between land tenure security and investment in soil 
conservation and, hence, production efficiency. This is an important food production relationship that should not be neglected if the country is truly striving towards being a giant in food productivity and hence in food self-sufficiency. Theoretically, this linkage has been predicated upon three major arguments. The first is that secured property right (land right) is expected to provide the guarantee for farmers to undertake long -term investment in land-improving and conservation measures, since there would be no fears of expropriation. Some have even argued that lack of secured land rights encourage farmers to adopt farming practices that leads to environmental degradation (Afikorah-Danquah, 1997).Second, it has been argued that secured land rights make it easier to use land as collateral to obtain loans to finance agricultural investments(Feder and Feeny, 1991).The third effect is hinged upon the possibilities of land transaction among users. Besley (1995) noted that investment in land -improving measures is encouraged if improved transfer rights enhance the factor mobility, making it easier to sell or rent their land.

Looking at the land right arrangement in the study area will therefore save us from making a wrong conclusion about the efficiency levels of the farmers as a result of non-inclusion of the variables that are believed to be correlates of water use efficiency based on the decision of the farmers to invest or not invest in soil conservation. Based on the two institutional settings we examined, we put forward two questions. The first is, were there any differences between the systems in the manner the farmers in both settings used resources? .Two: If the above question is in the affirmative, were these differences existing as result of the structures of the institutions stemming from government irrigation policies or they were just due to differences in farmers' intrinsic characteristics across farms in the two settings?. We thus, set forth two hypotheses, The first hypothesis is that there is no significant relationship in the manner farmers used irrigation resources between the two settings while the second is that efficiency indices of these two groups of farmers do not differ significantly. We will not be concentrating on details about the efficiency analysis here, but we employed the efficiency results in our T- test.

\subsection{Property Right Arrangements in the LNRBDA}

The property right arrangements in all the irrigation schemes under the under the RBDAs in Nigeria is predicated upon the Federal Government's alteration of the country's land tenure system some years back to suit the purpose of the establishment of these River Basins. Land tenure in Nigeria can be broadly classified into four types: these are communal, individual (private), customary and public (state) systems. The Communal systems of land tenure are widespread in the rural areas characterized with relatively low population density where majority of them are small scale farmers with small and fragmented holdings and where solidarity among groups is very organic; individual landownership is predominant in urban areas where population is dense and farming activities are not commonplace.

Customary land tenure systems in Nigeria are related to family and inheritance systems, and are based on the concept of group ownership of absolute rights in land, with individuals acquiring usufructuary rights. Customary land rights establish the basis for access to land resources and the opportunity to use land for productive purposes (Famoriyo,
1980). Famoriyo (1973) noted that under the customary rules of tenure, three principles were observed: first, each individual member of a landholding family was entitled to a portion of land - enough to feed himself and the members of his family; second, no member of the community could dispossess another of his or her stake in family land; and third, no one could alienate family members' interests in family land without the knowledge and consent of those members. Tenure systems under customary law vary but, in principle, are restricted to usufruct rights.

Public land tenure is an emergence of the Land Use Decree (Act) of 1978 in Nigeria. And this is a situation where all the land has been vested to the Governor of the State. This stipulates that the Government has the sole right to acquire any undeveloped land from any individual of corporation and also has the right to grant ownership of any undeveloped land to whom she will.

However, the system of Land use that exists in the chosen irrigation schemes under the RBDA is quite different from what operates in the farming communities outside the jurisdiction of the RBDA. Presently, two types of land tenure system exist in the chosen RBDA, namely the User Allocation System and the Farmer Occupier System. This is as a result of the partial alteration of the existing systems of land ownership by the Federal Government through the Federal Ministry of Agriculture and Water Resources when all the lands belonging to the RBDA were being acquired throughout the country after the sahelian drought of the early 1970s. When the dams in all the six geopolitical zones of the country were being constructed ,all the lands were acquired by the decree of the then military government and compensation were paid to the affected persons who were the original landlords while many of the communities were relocated. The farmers that are registered with the authority of Lower Niger River Basin Authority are called 'landless farmers' who do not have any right to plant the crop of their choice but must submit to the order of the authority. This tenure type is referred to as the User Allocation System and the farmers under this group account for the majority of those using irrigation facilities of the LNRBDA in Kwara and Kogi States. This fact may be different, though, in all the other RBDA in the remaining geopolitical zones of the country. Those in the Farmer Occupier System, however, are not registered with the LNRBDA authority for land allocation, because the land on which they operate do not belong to the authority. However, they make use of the water belonging to the authority

\section{Definition of variables}

Six crops altogether were cultivated in the schemes under both tenure conditions in the season of our survey. These are Maize, rice and four vegetables. The four vegetable crops are okra, tomatoes, watermelon and leafy vegetable. Some of the vegetable farmers practiced mixed cropping while the grains were solely cropped. For the purpose of convenience we have grouped together all the vegetable farms in each tenure system in all the schemes. For these farmers, outputs, fertilizer, herbicide, pesticide, and Seed were converted to monetary unit i.e the Naira value. Land was measured in $\mathrm{Ha}$, water in $\mathrm{m} 3$ and Labour in Man-day.

\subsection{Data}

Plot-level irrigation water use estimation and subsequent household interview were carried out in the chosen schemes. Multi-stage stratified sampling procedure was 
employed. This eventually led us to a random selection of 320 farmers operating 414 farms because some had two plots, from each of these schemes shared among the two types of tenancy arrangements that existed in the schemes.

The data collection was divided into two periods namely, the plot level data collection which enabled us to reasonably estimate the amount of water the small farmers used by direct pumping. The second is the household survey which was carried out after harvest. Field level data collection started in late December 2013 at the beginning of the irrigation season and ended in March ending/early April 2014 after all crops were harvested. Number of hours spent by farmers to pump water depended on the size of plot to irrigate and ability to fuel the pump. Pump capacity and record of hours spent in pumping water were taken by the irrigation officials in each of the schemes.

During the interview, information was gathered on the irrigation schemes included: household characteristics, farm and non-farm activities, quantities and costs of inputs used in production (capital, variable and overhead), volume and value of output, the quantity of water consumed, water demand characteristics and irrigation practices.

\section{Results and discussions}

\subsection{Descriptive Statistics}

The basic summary statistics of the variables used in the efficiency and T-tests analyses are presented in tables 1a1c.Talking about water, average water use for the vegetable farmers under the user allocation systems was $1722 \mathrm{~m}^{3}$ and $1174 \mathrm{~m}^{3}$ for farmers under the farmer occupier system
Average water use for maize farmers under the user allocation system was $1561 \mathrm{~m}^{3}$, and $1366 \mathrm{~m}^{3}$ in the farmer occupier system. Finally for the rice farmers, average water use under the user allocation system was $2038 \mathrm{~m}^{3}$ and $1501 \mathrm{~m}^{3}$ under the farmer occupier system. Water use for all the crops in the user allocation system was observed to be greater than what obtained for any of the crop in the farmer occupier system.

The farmers under both systems did not have any restraint from the authority to use water under any circumstances .Time spent in pump operation was determined by the capacity of farmers to fuel the pumps and run it for several hours .The farmers under the user allocation systems are financially well-off than those under the farmer occupier and therefore has capacity to pump water for more length of time. This category of people just come, gets allocation and hand over to labourers. They only come for supervision especially during fertilizer application and harvest. Land size in the user allocation for each crop was observed to be greater than land size under the farmer occupier. For all the crops, apart from rice, labour use was greater in the user allocation than in the farmer occupier systems. The amount spent on fertilizer, chemical and seed were greater in the User Allocation than in the farmer occupier systems for the vegetable crops. For maize, the quantities of these were greater in the user allocation than in the farmer occupier. However, in the rice farms, chemical and seed were greater in the Farmer occupier than in the User Allocation while fertilizer use was higher in the user allocation than the Famer occupier system.

Tables 1a: Descriptive statistics of the variables used in DEA analysis (Vegetable)

\begin{tabular}{|c|c|c|c|c|c|}
\hline \multicolumn{2}{|c|}{} & User Allocation. No of observations=55 & \multicolumn{2}{c|}{ Famer occupier. No of observations=45 } \\
\hline Variable & Units & Mean & Std.Dev. & Mean & Std.Dev. \\
\hline Output & (Naira) & 157,588 & Deve71833 & 107,274 & 49769 \\
Water & $\left(\mathrm{M}^{3}\right)$ & 1722 & 830. & 1174 & 449 \\
Land & (Ha) & 1.09 & ISSN: 20.76 & 0.70 & 0.33 \\
Labour & (Man-day) & 49 & 19 & 38 & 10 \\
Fertilizer & (Naira) & 9544 & 6612 & 4696 & 5152 \\
Herbicide & (Naira) & 4159 & 2227 & 2025 & 1667 \\
Pesticide & (Naira) & 3663 & 1954 & 3373 & 2113 \\
Seed & (Naira) & 6159 & 2589 & 5096 & 1639 \\
\hline
\end{tabular}

Tables 1b: Descriptive statistics of the variables used in DEA analysis (Maize)

\begin{tabular}{|c|c|c|c|c|c|}
\hline & & \multicolumn{2}{|c|}{ User Allocation. No of observations=89 } & \multicolumn{2}{c|}{ Famer occupier . No of observations=38 } \\
\hline Variable & Units & Mean & Std. Dev. & Mean & Std. Dev. \\
\hline Output & (Kg) & 4095 & 1158 & 1366 & 534 \\
Water & $\left(\mathrm{M}^{3}\right)$ & 1561 & 563 & 0.68 & 0.35 \\
Land & (Ha) & 1.73 & 0.54 & 41 & 12 \\
Labour & (Man-day) & 45 & 10 & 58 & 48 \\
Fertilizer & (Naira) & 79 & 37 & 1.63 & 1.41 \\
Herbicide & (Liters) & 3.7 & 1.18 & 1.36 & 1.24 \\
Pesticide & (Liters) & 4.15 & 0.94 & 44 & 10.59 \\
Seed & (Kg) & 47.25 & 10 & & \\
\hline
\end{tabular}

Tables 1c: Descriptive statistics of the variables used in DEA analysis (Rice)

\begin{tabular}{|c|c|c|c|c|c|}
\hline & & \multicolumn{2}{|c|}{ User Allocation. No of observations=125 } & Famer occupier. No of observations=62 \\
\hline Variable & Units & Mean & Std. Dev. & Mean & Std. Dev. \\
\hline Output & (Kg) & 3786 & 1388 & 3503 & 1383 \\
Water & $\left(\mathrm{M}^{3}\right)$ & 2038 & 415 & 1502 & 558 \\
Land & (Ha) & 1.38 & 0.53 & 1.16 & 0.51 \\
Labour & (Man-day) & 38 & 11 & 42 & 10.60 \\
Fertilizer & (Kg) & 168 & 55 & 117 & 59.71 \\
Herbicide & (Liters) & 3.4 & 1.18 & 3.69 & 1.20 \\
Pesticide & (Liters) & 2.91 & 1.28 & 3.80 & 1.08 \\
Seed & (Kg) & 41 & 11 & 43 & 13.07 \\
\hline
\end{tabular}




\subsection{T-TEST RESULTS}

Two separate T-tests were carried out in this study. One was to test whether there was a significant relationship in the manner resources were used by farmers in both settings while the other was that whether a significant relationship existed amongst the efficiency indices of the farmers in the two groups. The results of the T-tests are shown in tables $2 \mathrm{a}$ and $2 \mathrm{~b}$

The result reveals quite a combination of significant and insignificant relationships among the crop farmers in both institutional settings of the LNRBDA. From the result of the rice farms, there were significant differences between corresponding five resources in both FOS and UAS, thus leading us to reject the null hypotheses. These include water, land, labour, fertilizer and herbicide. Only two of the inputs showed a non-significant difference in the manner they were used in both systems. These were pesticide and seed. Among the maize farms in the UAS and FOS farms, four of the resources had significant relationship with each other in the way they were used. These are land, fertilizer, pesticide and herbicide. While the remaining three of the resources were not significantly different from each other in the manner they were used in both systems. Finally, among the vegetable farms, the use of five of the resources, like the situation in the rice farms were significant. These include water, land, labour, fertilizer and seed.

This t-test showcased the fact that the two tenure settings embraced an assortment of similarities and differences, conceivably in their structures and hence resource use pattern. This was probably embedded in the personal characteristics of the farmers in these two groups rather than the nature of both systems as established by government.

From the table of efficiency t-test, the pattern of the result is also non-uniform .It was an unequal share of significance and insignificance relationships amongst the efficiency indices of these two groups. This revealed the intention of the government in establishing both systems. It is an indication that government did not really establish one setting to have an upper hand over the other in terms of good performance as touching production. Though a more efficient group might emerge, as this was not unexpected, but the fact is that it was not basically by design. The inconsistent pattern of these relationships just pointed to the fact that the differences across the farms in both settings are based on the individual personal characteristics of the irrigators as opposed to the view that it was consequent upon government irrigation policies in the country which deliberately favour one system more than the other. If our submission is incorrect, then probably the government has strategically undermined her own effort to becoming self-sufficient in food production by deliberately not empowering the farmers in one of the setting to maximize its resource base.

Table 2a: T-test results for resource use in the UAS and FOS systems

\begin{tabular}{|c|c|c|c|c|c|c|}
\hline \multirow{2}{*}{ CROP } & \multicolumn{2}{|c|}{ FOS } & \multicolumn{2}{|c|}{ UAS } & \multirow{2}{*}{ P-VALUE } & \multirow{2}{*}{ DECISION } \\
\hline & Mean & variance & Mean & variance & & \\
\hline RICE & 80 & 8 & & & 0 & \\
\hline Water & 2038 & 17247 & 1502 & 311488 & $1.4 \times 10^{-9}$ & Reject \\
\hline Land & 1.38 & 0.28 & 1.16 & 0.26 & 0.01 & Reject \\
\hline Labour & 38 & 115 & 42 & 112 & 0.03 & Reject \\
\hline Fertilizer & 168 & 2981 & 117 & 3565 & $1.24 \times 10^{-7}$ & Reject \\
\hline Pesticide & 3.4 & 1.41 & 3.69 & 1.43 & 0.20 & Accept \\
\hline Herbicide & 2.91 & 1.66 & 3.80 & 1.16 & $1.74 \times 10^{-6}$ & Reject \\
\hline Seed & 41 & 127 & 43 & 171 & 0.40 & Accept \\
\hline maize & & & & & & \\
\hline Water & 1561 & 315965 & 1366 & 285547 & 0.08 & Accept \\
\hline Land & 1.73 & 0.29 & 0.68 & 0.12 & $6.68 \times 10^{-24}$ & Reject \\
\hline Labour & 45 & 109 & 41 & 133 & 0.09 & Accept \\
\hline Fertilizer & 79 & 1380 & 58 & 2368 & 0.02 & Reject \\
\hline Pesticide & 3.7 & 1.39 & 1.63 & 1.97 & $1.06 \times 10^{-10}$ & Reject \\
\hline Herbicide & 4.15 & 0.88 & 1.36 & 1.54 & $1.16 \times 10^{-17}$ & Reject \\
\hline Seed & 47.25 & 96 & 44 & 112 & 0.13 & Accept \\
\hline Vegetables & & & & & & \\
\hline Water & 1722 & 689022 & 1174 & 201848 & $6.39 \times 10^{-5}$ & Reject \\
\hline Land & 1.09 & 0.58 & 0.70 & 0.11 & $9.8 \times 10^{-4}$ & Reject \\
\hline Labour & 49 & 377 & 38 & 95.24 & $2.32 \times 10^{-}$ & Reject \\
\hline Fertilizer & 9544 & $4.37 \times 10^{7}$ & 4696 & $2.66 \times 10^{7}$ & $7.95 \times 10^{-5}$ & Reject \\
\hline Pesticide & 4159 & $4.96 \times 10^{6}$ & 2025 & $2.78 \times 10^{6}$ & 0.07 & Accept \\
\hline Herbicide & 3663 & $3.82 \times 10^{6}$ & 3373 & $4.47 \times 10^{6}$ & 0.48 & Accept \\
\hline Seed & 6159 & $6.70 \times 10^{6}$ & 5096 & $2.69 \times 10^{6}$ & 0.01 & Reject \\
\hline
\end{tabular}


Table 2b: T-test results for efficiency indices in the UAS and FOS systems

\begin{tabular}{|c|c|c|c|c|c|c|}
\hline \multirow{2}{*}{ CROP/EFFICIENCY } & \multicolumn{2}{|c|}{ FOS } & \multicolumn{2}{|c|}{ UAS } & \multirow{2}{*}{ P-VALUE } & \multirow{2}{*}{ DECISION } \\
\hline & Mean & variance & Mean & variance & & \\
\hline \multicolumn{7}{|l|}{ Rice } \\
\hline CRS TE & 0.85 & 0.017 & 0.77 & 0.040 & 0.004 & Reject \\
\hline VRS TE & 0.92 & 0.007 & 0.90 & 0.020 & 0.28 & Accept \\
\hline CRSEE & 0.58 & 0.021 & 0.53 & 0.041 & 0.008 & Reject \\
\hline VRSEE & 0.71 & 0.038 & 0.75 & 0.0095 & 0.075 & Accept \\
\hline CRSAE & 0.68 & 0.016 & 0.68 & 0.021 & 0.91 & Accept \\
\hline VRSAE & 0.82 & 0.0072 & 0.72 & 0.021 & $2.4 \times 10^{-31}$ & Reject \\
\hline \multicolumn{7}{|l|}{ Maize } \\
\hline CRS TE & 0.88 & 0.008 & 0.95 & 0.006 & $8.73 \times 10^{10}$ & Reject \\
\hline VRS TE & 0.95 & 0.005 & 0.97 & 0.004 & 0.041 & Reject \\
\hline CRS EE & 0.69 & 0.014 & 0.68 & 0.026 & 0.0057 & Reject \\
\hline VRS EE & 0.79 & 0.020 & 0.72 & 0.033 & 0.48 & Accept \\
\hline CRS AE & 0.60 & 0.015 & 0.72 & 0.023 & 0.159 & Accept \\
\hline VRS AE & 0.74 & 0.029 & 0.74 & 0.030 & 0.10 & Accept \\
\hline \multicolumn{7}{|l|}{ VEGITABLE } \\
\hline CRS TE & 0.89 & 0.019 & 0.95 & 0.004 & 0.0067 & Reject \\
\hline VRS TE & 0.93 & 0.014 & 0.96 & 0.003 & 0.024 & Reject \\
\hline CRS EE & 0.54 & 0.025 & 0.76 & 0.032 & $1.83^{*} 10^{-9}$ & Reject \\
\hline VRS EE & 0.65 & 0.033 & 0.64 & 0.043 & 0.80 & Accept \\
\hline CRS AE & 0.60 & 0.022 & 0.67 & 0.044 & 0.062 & Accept \\
\hline VRS AE & 0.70 & 0.025 & 0.78 & 0.043 & 0.046 & Reject \\
\hline
\end{tabular}

CRS=Constant Return to Scale; VRS=Variable Return to Scale; TE=Technical Efficiency ;AE= Allocative Efficiency and $\mathrm{EE}=$ Economic Efficiency

\section{Conclusion and Policy Issues}

The study employed T-test analyses to examine the relationships that existed between two types of land institutional setting in the Lower Niger River Basin Development Authority of Kwara and Kogi States of North Central Nigeria, among irrigation farmers operating under these two different tenure conditions. We put forward two hypotheses to understand if there were any differences between the systems and to know whether these differences were about the structures of the institutions as a result of government irrigation policies or they were just due to differences in farmers' characteristics across farms in the two settings.

The t-tests showed that there existed discrepancies on one part and similarities on the other in the manner the farmers in the UAS and FOS used irrigation resources and also in their efficiency indices. Consequently, government did not intentionally establish one setting to be superior to the other in terms of production performance. We recommend that government should keep on maintaining their oversight functions and supervisory roles in these schemes without deprivations of any of the settings in their access to basic irrigation resources in the area and the nation as a whole. The farmers in both settings should also remain proactive and ready to improve on their production targets year in and year out.

\section{References}

[1] Afikorah-Danquah, S. (1997): Local Resource Management in the Forest -Savannah. Transition Zone: The case study of Whenchi District, Ghana IDS Bulletin 28 (4):163-184.

[2] Besley T. (1995): Property Rights and Investment Incentive: Theory and Evidence from Ghana. The Journal of Political Economy 103:903-937

[3] Famoriyo, S. (1980). Land Tenure Systems and Small Farmers in Nigeria. In S.O. Oludipe, J.A. Emeka \& V.E. Bello-Osagie, eds. Nigeria - small farmers. Problems and prospects in integrated rural development, $p$. 115-132. CARD, University of Ibadan, Ibadan, Nigeria.

[4] Famoriyo, S. (1973). Land Tenure and Food Production. Land Tenure Center Newsletter No. 41. University of Wisconsin, Madison, USA.

[5] Feder, G. and D. Feeny, (1991):Land Tenure and Property Rights : Theory and Implication for Development Policy World Bank Economic Review 5: 135-153

[6] Godfray, H.C.J., Beddington, J.R., Crute, I.R., Haddad, L., Lawrence, D., Muir, J.F., Pretty, J., Robinson, S., homas, S. M., Toulmin, C., 2010. Food security: the challenge of feeding 9 billion people. Science 327 (5967), 812 - 818

[7] Holden S.T. and, Hosaena G, (2016) Land tenure reforms, tenure security and food security in poor agrarian economies: Causal linkages and research gaps Global Food Security 10(2016) 21-28

[8] Holden, S.T., Otsuka, K., 2014. The roles of land tenure reforms and land markets in the context of population growth and land use intensification in Africa. Food Pol. 48, $88-97$.

[9] Lambin, E.F., Meyfroidt, P., 2011. Global land use change, economic globalization, and the looming land scarcity. Proc. Natl. Acad. Sci. USA 108 (9), 3465 3472.

[10] Maxwell, D., Wiebe, K., 1999. Land tenure and food security: exploring dynamic linkages. Dev.Change 30 (4), 825-849

[11] Victor Owusu, Jan Willem Gunning and Kees Burger (2007) Do Tenure Differences Influence the Improvement of Quality of Rented Land? Empirical Evidence from Rural Ghana.Paper presentation at the $106^{\text {th }}$ seminar of the EAAE Pro-poor development in low income countries: Food, agriculture, trade, and environment 25-27 October 2007 - Montpellier, France Vuuren W. V and P. Ysselstein (1986) Relationship between land tenure and soil productivity Canadian J. Soil Sci. 66:: 357-366. 